\title{
Commentary \\ Myocardial Doppler velocities as a marker of prognosis in the ICU
}

\author{
Jan Poelaert ${ }^{1}$ and Carl Roosens ${ }^{2}$
}

1Department of Anesthesiology, University Hospital Brussels, Laarbeeklaan 101, 1090 Brussels, Belgium
2Department of Intensive Care Medicine, Ghent University Hospital, De Pintelaan 185, B-9000 Gent, Belgium

Corresponding author: Jan Poelaert, jan.poelaert@uzbrussel.be

Published: 26 October 2007

Critical Care 2007, 11:167 (doi:10.1186/cc6129)

This article is online at http://ccforum.com/content/11/5/167

(C) 2007 BioMed Central Ltd

See related research by Sturgess et al., http://ccforum.com/content/11/5/R97

\begin{abstract}
Relatively simple measures of echocardiography and Doppler, as left ventricular end-systolic area and volume, should be taken in consideration when performing a Doppler echocardiographic examination, as they could have both clinical and prognostic value.
\end{abstract}

Echocardiography made an enormous technological evolution from $\mathrm{M}$ mode imaging in the sixties, to two-dimensional, colour, pulsed and continuous wave Doppler echocardiography to come to some rather sophisticated items such as myocardial Doppler imaging, colour Doppler analysis of flow velocities and speckle tracking. The prognostic potential of these new techniques has not yet been elucidated, in particular in critically ill patients. In this issue of Critical Care, Sturgess et al. retrospectively analyzed a cohort of intensive care unit patients with respect to outcome [1].

Doppler myocardial imaging is a newer cardiac ultrasound technique in which the Doppler signals are processed following reflection of ultrasound beams originating within the myocardium. With this technique, pulsed Doppler signals are analyzed by performing spectral or power analysis allowing more extensive analysis of diastolic function, when used in conjunction with transmitral and pulmonary venous Doppler flow pattern analysis. Although Isaaz et al. already described pulsed Doppler recordings of myocardial tissue motion using a simple sample volume technique in 1989 [2], little clinical value was awarded to this technique. A single pulsed Doppler myocardial velocity sample volume interrogation inherently permits the analysis of regional wall motions, related to electrical and mechanical cardiac events. Echocardiographs have to allow high amplitude, low velocity information. A few years later however, it became clear that visualization of tissue motion had indeed a potential for clinical use [3]. Colour Doppler myocardial imaging permits accurate measurement of myocardial velocities at a large number of adjacent intramural sites. Doppler myocardial imaging allows estimation of both longitudinal systolic and diastolic function of the ventricles.

The present study retrospectively analyzed a series of data in critically ill patients with respect to myocardial Doppler imaging as part of a general echocardiographic examination. Although the decision to perform the echo investigation was taken on a clinical basis in the sickest patients, and therefore contains a considerable selection bias both in terms of patient selection and timing, some remarkable issues were put forward. The most prominent conclusion is the important prognostic value of left ventricular end-systolic volume, related with outcome. From the literature, it is well-known that presence of a dilated cardiomyopathy has a strong inverse relationship with outcome, not only in adults but also in children [4-8]. Also in mitral valve disease, echocardiographic findings of a left ventricular end-systolic diameter above $4.5 \mathrm{~cm}$ strongly hampers two-years survival [9]. Therefore, the importance of the presence of a dilated left ventricle in a critically ill patient should not be denied.

The second finding of this study was also not astonishing: Sturgess et al. found only a weak relationship between the pulmonary artery occlusion pressure and the ratio of the early filling wave velocity at the level of the mitral valve $(E)$ and the analogue myocardial velocity assessed at the mitral annulus with tissue Doppler imaging ( $\left.E^{\prime}\right)$. The authors found no correlation between E/E' and some other static variables of preload: left ventricular end-diastolic volume, the inferior caval vein diameter and left atrial area or volume. The influence of some dynamic load variables as respiratory induced variations of the inferior caval vein diameter $[10,11]$ was, however, not tested. In addition, left area or volume is not only a static variable of preload, but also related to left ventricular systolic function (in particular it is important whenever mitral regurge is present) and both atrial and ventricular compliance. 
Finally, there is the discussion on load dependency of E'. This issue remains controversial and not at all completely clarified, as outlined in a recent commentary [12]. In particular, the disparity of the mitral annular motion as described recently $[13,14]$, should be evaluated more closely, but indeed could be of certain help in understanding differences in diastolic mitral annular motion as exemplified with E'.

Whereas Doppler myocardial imaging allows more precise discrimination of the phase of diastolic dysfunction, Sturgess et al. clearly demonstrated that relatively simple echo variables, as left ventricular end-systolic volume, retain their clinical and even prognostic value and therefore should not be forgotten whenever performing an echocardiographic investigation.

\section{Competing interests}

The authors have no competing interests.

\section{References}

1. Sturgess D, Marwick T, Joyce C, Jones M, Venkatesh B: Tissue Doppler in critical illness: a retrospective cohort study. Crit Care 2007, 11:R97.

2. Isaaz K, Thompson A, Ethevenot G, Cloez JL, Brembilla B, Pernot $\mathrm{C}$ : Doppler echocardiographic measurement of low velocity motion of the left ventricular posterior wall. Am J Cardiol 1989, 64:66-75.

3. McDicken WN, Sutherland GR, Moran CM, Gordon LN: Colour Doppler velocity imaging of the myocardium. Ultrasound Med Biol 1992, 18:651-654.

4. Faris R, Coats AJ, Henein MY: Echocardiography-derived variables predict outcome in patients with nonischemic dilated cardiomyopathy with or without a restrictive filling pattern. Am Heart J 2002, 144:343-350.

5. Huh J, Noh Cl, Yun YS: The usefulness of surface electrocardiogram as a prognostic predictor in children with idiopathic dilated cardiomyopathy. J Korean Med Sci 2004, 19:652-655.

6. Knuuti J, Sundell J, Naum A, Engblom E, Koistinen J, Ylitalo A, Stolen KQ, Kalliokoski R, Nekolla SG, Bax KE et al: Assessment of right ventricular oxidative metabolism by PET in patients with idiopathic dilated cardiomyopathy undergoing cardiac resynchronization therapy. Eur J Nucl Med Mol Imaging 2004, 31:1592-1598.

7. La Vecchia L, Varotto L, Zanolla L, Spadaro GL, Fontanelli A: Right ventricular function predicts transplant-free survival in idiopathic dilated cardiomyopathy. J Cardiovasc Med (Hagerstown) 2006, 7:706-710.

8. Lewis AB: Prognostic value of echocardiography in children with idiopathic dilated cardiomyopathy. Am Heart J 1994, 128: 133-136.

9. Hung J, Papakostas L, Tahta SA, Hardy BG, Bollen BA, Duran $\mathrm{CM}$, Levine RA: Mechanism of recurrent ischemic mitral regurgitation after annuloplasty: continued LV remodeling as a moving target. Circulation 2004, Suppl 1:ll85-90.

10. Barbier C, Loubieres $Y$, Schmit C, Hayon J, Ricome JL, Jardin F, Vieillard-Baron A: Respiratory changes in inferior vena cava diameter are helpful in predicting fluid responsiveness in ventilated septic patients. Intensive Care Med 2004, 30:1740-1746.

11. Feissel M, Michard F, Faller JP, Teboul JL: The respiratory variation in inferior vena cava diameter as a guide to fluid therapy. Intensive Care Med 2004, 30:1834-1837.

12. Poelaert J, Roosens C: Is tissue Doppler echocardiography the Holy Grail for the intensivist? Crit Care 2007, 11:135.

13. Glasson JR, Komeda MK, Daughters GT, Niczyporuk MA, Bolger AF, Ingels NB, Miller DC: Three-dimensional regional dynamics of the normal mitral anulus during left ventricular ejection. $J$ Thorac Cardiovasc Surg 1996, 111:574-585.

14. Gorman JH, 3rd, Gupta KB, Streicher JT, Gorman RC, Jackson BM, Ratcliffe MB, Bogen DK, Edmunds LH, Jr.: Dynamic threedimensional imaging of the mitral valve and left ventricle by rapid sonomicrometry array localization. J Thorac Cardiovasc Surg 1996, 112:712-726. 